\title{
BMJ Open Oxidative stress and DNA damage in a long-term hexavalent chromium- exposed population in North China: a cross-sectional study
}

\author{
Jing Xu, ${ }^{1,2}$ Meiduo Zhao, ${ }^{1,2}$ Lu Pei, ${ }^{1,2}$ Ruiming Zhang, ${ }^{1,2}$ Xiaolin Liu, ${ }^{3}$ Lanping Wei, ${ }^{4}$ \\ Mingan Yang, ${ }^{5}$ Qun $X u^{1,2}$
}

To cite: Xu J, Zhao M, Pei L, et al. Oxidative stress and DNA damage in a long-term hexavalent chromium-exposed population in North China: a cross-sectional study. BMJ Open 2018;8:e21470. doi:10.1136/ bmjopen-2017-021470

- Prepublication history and additional material for this paper are available online. To view these files, please visit the journal online (http://dx.doi org/10.1136/bmjopen-2017021470).

Received 3 January 2018 Revised 9 May 2018 Accepted 18 May 2018

\section{Check for updates}

${ }^{1}$ Department of Epidemiology and Biostatistics, Institute of

Basic Medical Sciences Chinese Academy of Medical Sciences, School of Basic Medicine, Peking Union Medical College, Beijing, China

${ }^{2}$ Center of Environmental and Health Sciences, Chinese Academy of Medical Sciences, Peking Union Medical College, Beijing, China

${ }^{3}$ College of Public Health, Jinzhou Medical University, Jinzhou, China

${ }^{4}$ Department of Cardiology, Jinzhou Central Hospital, Jinzhou, China

${ }^{5}$ Division of Biostatistics and Epidemiology, Graduate School of Public Health, San Diego State University, San Diego, California, USA

Correspondence to

Dr Qun Xu;

xuqun@ibms.cams.cn

\section{ABSTRACT}

Objective The International Agency for Research on Cancer classifies hexavalent chromium ( $\mathrm{Cr}(\mathrm{VI}))$ as a human carcinogen. As reported, cancer mortality was higher in $\mathrm{Cr}(\mathrm{VI})$-contaminated areas. Scientists have recommended studying its health impact on people living in contaminated areas. This study aims to evaluate the health risk for people living in $\mathrm{Cr}(\mathrm{VI})$-contaminated areas.

Design We conducted a cross-sectional study in rural areas of north-eastern China. Malondialdehyde (MDA), glutathione peroxidase (GSH-Px), superoxide dismutase (SOD) and catalase (CAT) were used as oxidative stress parameters, and 8-hydroxy-2 deoxyguanosine (8-OHdG) as a DNA damage biomarker. We collected information on demographics, lifestyles and length of residence from all participants using a questionnaire. Biological specimens and environmental media samples were collected on the same day as the survey was done. We used t-test, $\chi^{2}$ test, Wilcoxon rank-sum test and multivariate linear regression analysis.

Participants The study included 319 participants exposed to $\mathrm{Cr}(\mathrm{VI})$ and 307 unexposed participants, with 447 women and 179 men. These participants met the following criteria: (1) living in the areas for more than 10 years; (2) age older than 18 years; and (3) without occupational chromium exposure.

Results Our study revealed that serum concentration of MDA $(p<0.001)$, serum activities of CAT $(p<0.001)$ and GSH-Px $(\mathrm{p}<0.001)$, as well as urine concentration of $8-0 \mathrm{HdG}(p=0.008)$ in the exposed group were significantly higher than those in the unexposed group. However, serum SOD activity was significantly lower in the exposed group, compared with that in the unexposed group $(p<0.001)$. $\mathrm{Cr}(\mathrm{VI})$ exposure and smoking have an interaction effect on GSH-Px activity $(p<0.05)$. Cr(VI) exposure and alcohol drinking also have an interaction effect on GSH-Px activity $(p<0.05)$. Longer residence in the exposed areas increased the oxidative levels $(p<0.05)$.

Conclusions The findings of this study showed elevated oxidative stress and DNA damage in people exposed to $\mathrm{Cr}(\mathrm{VI})$.

\section{INTRODUCTION}

Hexavalent chromium (Cr(VI)) compounds are commonly found in industrial settings

\section{Strengths and limitations of this study}

To the authors' best knowledge, this is the first paper to study the relationship between hexavalent chromium exposure and oxidative stress levels in non-occupationally exposed people.

- Health survey and environmental surveillance for hexavalent chromium were conducted concurrently in previously environmentally polluted areas.

- We collected individual demographic characteristics and lifestyle data to minimise possible confounding in the analysis.

- The main limitation is that individual exposure data are not obtained.

- In addition, demographic homogeneity of the exposed and unexposed groups was not so satisfactory.

such as chromite ore mining, pigment production, leather tanning, manufacture of wood preservatives and in anticorrosive processes in the production of kitchen utensils (electroplating). ${ }^{1}$ Heavy metals from anthropogenic sources can be transported into the air, deposited on the soil surface and then penetrate into the water. ${ }^{23}$ High concentrations of heavy metals in the soil may correlate with high concentrations in plants. ${ }^{4}$ People living near contaminated areas may be faced with health risks due to heavy metal concentrations in food or water. ${ }^{5}$ The general population may be exposed to chromium $(\mathrm{Cr})$ through contaminated water, food or air. ${ }^{6}$

According to the International Agency for Research on Cancer monographs on the evaluation of carcinogenic risks to humans, $\mathrm{Cr}(\mathrm{VI})$ is considered a human carcinogen. ${ }^{7-10}$ Based on numerous studies in occupational epidemiology, inhalation of $\mathrm{Cr}(\mathrm{VI})$ correlated with increased risk for lung cancer. ${ }^{9}$ Numerous epidemiological studies also reported an increased risk of cancer morbidity, especially 
for gastrointestinal cancer, in populations exposed to $\mathrm{Cr}(\mathrm{VI}) .{ }^{711}$ For these reasons, $\mathrm{Cr}(\mathrm{VI})$ contamination may pose a serious threat to population health.

Toxicity and carcinogenicity of $\mathrm{Cr}(\mathrm{VI})$ are possibly related to increased oxidative stress. ${ }^{12}$ When $\mathrm{Cr}(\mathrm{VI})$ is reduced to a lower oxidative state, many reactive oxygen species (ROS) form. Therefore, one of the most important negative effects caused by extraneous $\mathrm{Cr}(\mathrm{VI})$ is the formation of ROS during the reduction of $\mathrm{Cr}(\mathrm{VI})$ in cells. ${ }^{13}$ The generated hydroxyl radicals are able to react with DNA bases. For this reason, the substance that is the best marker for oxidative damage in an organism is 8-hydroxy-2'-deoxyguanosine (8-OHdG).$^{14}$ Reduction of the extra ROS can be achieved through enzymatic and non-enzymatic reactions. Oxidative stress results from an imbalance between the production of free radicals and the antioxidant defence system, leading to a reduced capacity to detoxify free radicals and repair damage. ${ }^{15}$ The attack of free radicals on cellular components has been studied in various pathological conditions such as in cardiovascular diseases and cancers. ${ }^{16-18}$ Animal experiments indicate that $\mathrm{Cr}(\mathrm{VI})$ exposure results in the depletion of the antioxidant defence elements, subsequently causing lipid peroxidation. ${ }^{19}$ Lipid peroxidation has been suggested to play a key role in many biological processes, and malondialdehyde (MDA) has long been used as a marker for secondary products of lipid peroxidation. ${ }^{20}$

Due to industrial expansion in the mid-20th century, the western suburban areas of Jinzhou city in Liaoning province in north-east China have been environmentally polluted by $\mathrm{Cr}(\mathrm{VI}){ }^{8}$ Multiple studies have shown that occupational exposure to $\mathrm{Cr}(\mathrm{VI})$ induced changes in oxidative stress and oxidative damage. However, there is only a limited amount of human data on the environmental exposure of $\mathrm{Cr}(\mathrm{VI})$ in terms of oxidative stress and oxidative damage. People living close to a ferroalloy plant could be exposed to $\mathrm{Cr}(\mathrm{VI})$ by respiratory route, and by digestive and cutaneous routes. Mortality rates of stomach cancer and lung cancer in areas where water was contaminated by $\mathrm{Cr}(\mathrm{VI})$ were much higher in comparison with those in areas without contamination. ${ }^{71}$ All the $\mathrm{Cr}(\mathrm{VI})$-polluted areas in this study are along the Nver River, where the water has been polluted by the ferroalloy factory. Previous studies have shown that the highest $\mathrm{Cr}$ concentration in well water of this area was $20 \mathrm{mg} / \mathrm{L} .{ }^{11} \mathrm{~A}$ ferroalloy factory was established here in 1960, and since then people living near the factory have been exposed to $\operatorname{Cr}(\mathrm{VI})$. After long-time exposure, a series of health risks may be induced. Therefore, this study mainly aims to investigate whether environmental exposure to $\mathrm{Cr}(\mathrm{VI})$ can induce changes in oxidative stress and oxidative damage.

\section{MATERIALS AND METHODS}

\section{Study design and population}

We conducted a cross-sectional study in the villages of Jinzhou city located in Liaoning province in north-east
China to evaluate changes in the levels of oxidative stress and oxidative damage caused by $\mathrm{Cr}(\mathrm{VI})$. We enrolled 626 participants, 447 women and 179 men, in the study who met the following criteria: (1) living in the areas for more than 10 years; (2) age older than 18 years; and (3) without occupational $\mathrm{Cr}$ exposure. The participants were divided into exposed and unexposed groups based on their geographical position, historical data and environmental Cr levels, with A1 village, $\mathrm{A} 2$ village and $\mathrm{A} 3$ village as the exposed areas, and $\mathrm{B} 1$ village, $\mathrm{B} 2$ village and $\mathrm{B} 3$ village as the unexposed areas. Figure 1 shows a map of the study areas, which was generated using the ArcGIS Online basemap publicly available and produced by the ArcGIS V.10.2 software. All the exposed villages were along the contaminated river, less than $10 \mathrm{~km}$ away from the ferroalloy factory, with high Cr levels in the environment. The unexposed villages were at least $50 \mathrm{~km}$ away from the factory, with relatively low $\mathrm{Cr}$ levels in the environment (figure 1, table 1). All enrolled individuals signed the informed consent forms.

\section{Questionnaire survey}

Specially trained undergraduate and postgraduate students were involved in the face-to-face interviews with the participants using an ad hoc questionnaire, which was designed to collect information on sociodemographics (sex, birth date, survey date, education level, occupation status, personal income, marital status and length of residence), lifestyles (eg, smoking, alcohol drinking), as well as occupational exposure to $\mathrm{Cr}(\mathrm{VI})$ and other related issues.

\section{Blood and urine sample collection}

Whole blood was collected into an EDTA anticoagulation tube. Serum was collected into a non-anticoagulation tube and obtained by centrifugation at $3500 \mathrm{rpm}$ for $10 \mathrm{~min}$ to precipitate the cellular components. Urine specimen was collected into a bacteria-free centrifuge tube. All the samples were transported by an ice box to guarantee their quality. Subsequently, all the laboratory examinations were conducted within 24 hours, and the remaining samples were stored at $-80^{\circ} \mathrm{C}$ for later analysis.

\section{MDA concentration in serum, and serum CAT, SOD and GSH-Px activity measurements}

The serum concentration of malondialdehyde (MDA) and the serum activities of catalase (CAT), superoxide dismutase (SOD) and glutathione peroxidase (GSH-Px) were determined with Malondialdehyde (MDA) Assay Kit (thiobarbituric acid method), Catalase (CAT) Assay Kit (visible light), Total Superoxide Dismutase (T-SOD) Assay Kit (hydroxylamine method) and Glutathione Peroxidase (GSH-Px) Assay Kit (colourimetric method), which were supplied by Nanjing Jiancheng Bioengineering Institute (China). 


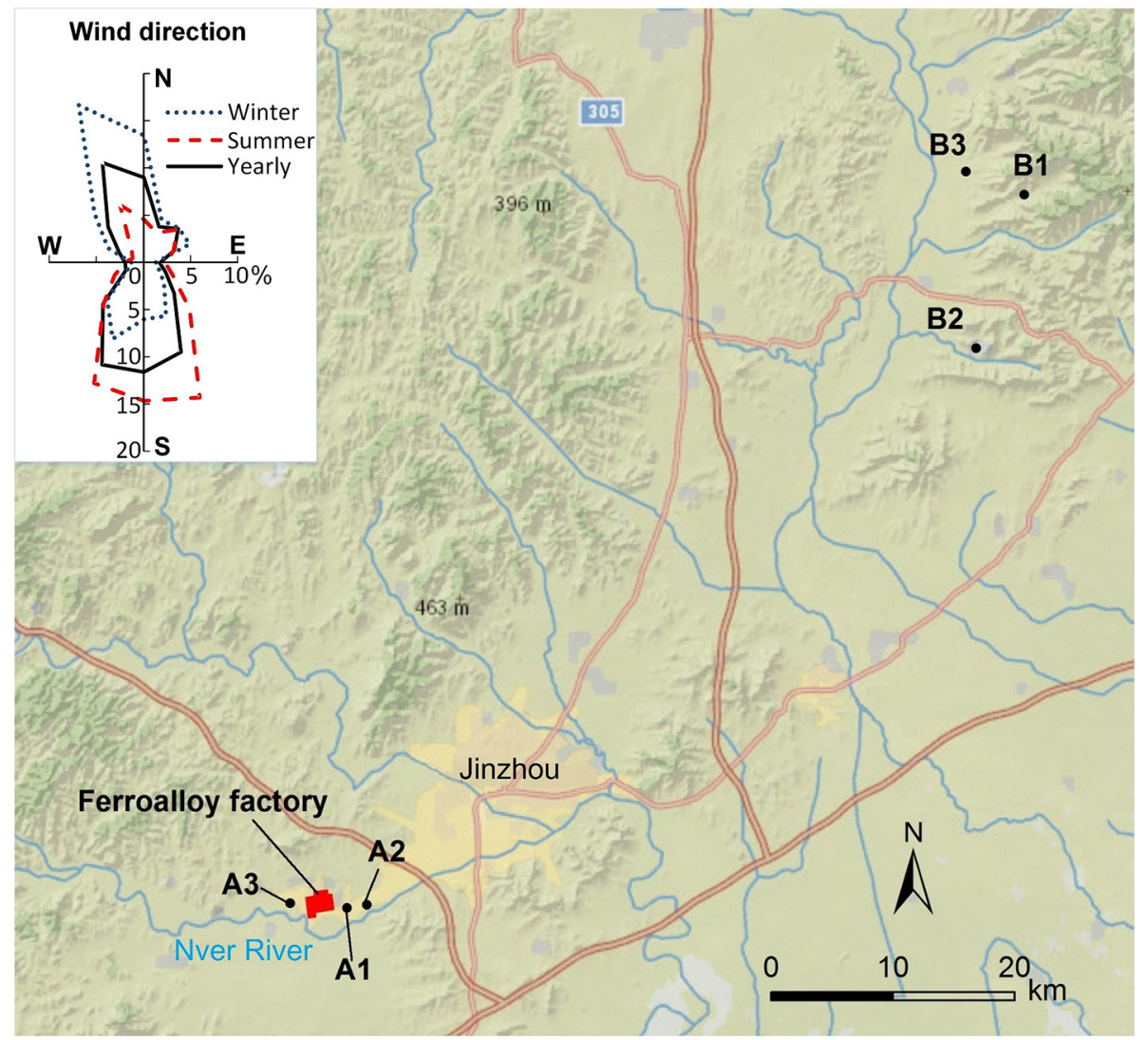

Figure 1 Position of six villages where the survey was conducted, with A1 village, A2 village and A3 village as exposed areas, and $B 1$ village, B2 village and B3 village as unexposed areas. All the exposed villages were along the contaminated river, less than $10 \mathrm{~km}$ away from the factory. The unexposed villages were at least $50 \mathrm{~km}$ away from the factory. This map was generated using the ArcGIS Online basemap, which was publicly available and produced by the ArcGIS V.10.2 software.

\section{Urinary 8-0HdG and urinary creatinine measurements}

Urine concentration of 8-hydroxy-2'- deoxyguanosine (8-OHdG) was determined with an ELISA kit (JaICA, Japan, 8-OHdG ELISA kit). To minimise the influence of urine density difference among participants, the 8-OHdG concentration was regulated with urine creatinine (Cre), which was determined by ELISA using a commercial kit from Roche Pharmaceutical (Switzerland).

\section{Collection and testing of environmental media samples}

Environmental media samples were collected in the studied area at the same time as the survey was conducted.
We collected groundwater samples from $7 \mathrm{~m}$ or $8 \mathrm{~m}$ deep wells in the yards of the participant's house and soil samples from the field surface. Air samples were collected 24 hours a day for 5 days in three exposed villages and three unexposed villages, with sampling membranes changed every 24 hours. All samples were stored in refrigerators at $4^{\circ} \mathrm{C}$ for further laboratory analysis. The concentration of $\mathrm{Cr}(\mathrm{VI})$ in the groundwater was determined by diphenylcarbazide spectrophotometric method with a detection limit of $0.004 \mathrm{mg} / \mathrm{L} .{ }^{21}$ If the detection result was lower than the limit, half of the detection limit was used in the statistical analysis. The total Cr level of soil

Table 1 Chromium levels in varied samples collected from the study areas in 2016

\begin{tabular}{|c|c|c|c|c|c|}
\hline \multirow[b]{2}{*}{ Samples } & \multicolumn{2}{|c|}{ Exposed areas } & \multicolumn{2}{|c|}{ Unexposed areas } & \multirow[b]{2}{*}{$P$ values* } \\
\hline & $\mathbf{n}$ & $\begin{array}{l}\text { Median } \\
\text { (min, Q1, Q3, max) }\end{array}$ & $\mathbf{n}$ & $\begin{array}{l}\text { Median } \\
\text { (min, Q1, Q3, max) }\end{array}$ & \\
\hline Groundwater (mg/L)† & 13 & $\begin{array}{l}0.002 \\
(0.002,0.002,1.1,2.5)\end{array}$ & 18 & $\begin{array}{l}0.002 \\
(0.002,0.002,0.002,0.002)\end{array}$ & 0.0017 \\
\hline Soil $(\mathrm{mg} / \mathrm{kg})$ & 45 & $\begin{array}{l}69.5 \\
(48.7,59.1,93.9,417.1)\end{array}$ & 30 & $\begin{array}{l}29.2 \\
(20.1,26.4,30.4,41.11)\end{array}$ & $<0.001$ \\
\hline $\operatorname{Air}\left(n g / m^{3}\right)$ & 15 & $\begin{array}{l}19.3 \\
(10.1,13.7,28.4,82.9)\end{array}$ & 15 & $\begin{array}{l}13.12 \\
(5.0,10.9,16.8,18.7)\end{array}$ & 0.015 \\
\hline
\end{tabular}

*Wilcoxon rank-sum test was used to compare the difference between the exposed areas and unexposed areas.

†Hexavalent chromium. 
and air was determined by atomic absorption spectrophotometry and inductively coupled plasma optical emission spectrometry. ${ }^{22} 23$

\section{Quality control}

All investigators would explain the exact meaning of each question to the participants given that most of them did not have a higher education level. After the survey, investigators would check the integrity of the questionnaire completed and make sure that blood and urine specimens were collected. To ensure that every participant had a unique identification to match their questionnaires and biological specimens, a standard coding system was used. The laboratory staff were required to strictly follow the protocol and instructions of the kit in conducting the analysis. Absorbance for each specimen was measured three times, using the average as its final value. If its fluctuation was more than $50 \%$ among the three absorbance measures, the analysis would be reconducted. Testing of the environmental samples was strictly conducted according to the protocol.

\section{Statistical analysis}

EpiData V.3.1 software was used for input of original data collected from questionnaires with double-entry, checking for logic errors to ensure accuracy. Summary statistics were provided for both categorical (proportion) and continuous variables. Unpaired t-test was used to compare two mean values and $\chi^{2}$ test was used to compare categorical variables. If the data did not meet the normal distribution, Wilcoxon rank-sum test was used.

Subsequently, multiple general linear regression analysis was performed to analyse the main factors that affected the levels of oxidative stress and oxidative damage. To deal with skewed data, we used log-transformation for the variable 8-OHdG in our analysis. Occupation and marital status were not used in the multivariate regression analysis because these two variables had less than $10 \%$ of cases in a group. All the expected and observed numbers with the variables used in the multivariate regression model had more than 5 in each cell of the two-way tables.

To explore the relationship between $\mathrm{Cr}(\mathrm{VI})$ exposure and oxidative stress and damage, we conducted further analysis stratified by age, sex, smoking status, alcohol drinking and education level, respectively, as well as stratified by disease status because some diseases could affect oxidative levels. Interaction terms were added into the models to explore potential interactions between variables. We conducted a stratified analysis in the subgroups of first exposure before and after 18 years old to explore the relationship between the length of residence and oxidative levels in the exposed group, since age at first exposure and length of residence may have an effect on the oxidative levels. The statistical significance of a linear trend was tested by including the median of each category as a continuous variable in the regression model. Statistical significance was defined as $p$ value less than
0.05 (two-tailed). All analyses were conducted using the SAS V.9.4 software.

\section{Patients and public involvement}

Patients and the public were not involved in this study.

\section{RESULTS}

Table 1 presents the $\mathrm{Cr}$ level in groundwater, soil and air. $\mathrm{Cr}(\mathrm{VI})$ was not detected in any groundwater samples of the unexposed areas, while the maximum concentration of $\mathrm{Cr}(\mathrm{VI})$ in the groundwater samples in the exposed areas reached $2.5 \mathrm{mg} / \mathrm{L}$, with a statistically significant difference $(\mathrm{p}=0.0017)$. The total $\mathrm{Cr}$ concentrations in soil and air samples from the exposed areas both are significantly higher than unexposed areas, with $\mathrm{p}$ values of less than 0.001 and 0.015 , respectively.

Table 2 presents the demographic characteristics of the 626 participants living in the exposed and unexposed areas, 319 in the exposed villages and 307 in the unexposed. Table 2 shows there is no significant difference in occupation, marital status or personal income between the exposed and unexposed groups. However, significant differences $(p<0.05)$ with respect to age, sex, education level, smoking status and alcohol drinking between the two groups were found. Specifically, participants in the exposed group are older, more likely to be female, more likely to have higher education level and less likely to smoke or drink than in the unexposed group.

The results of the multivariate regression analysis showed that serum MDA concentration $(\mathrm{p}=0.0001)$, serum CAT activity $(\mathrm{p}<0.0001)$, serum GSH-Px activity $(\mathrm{p}<0.0001)$ and urine concentration of $8-\mathrm{OHdG}(\mathrm{p}=0.0117)$ were significantly higher in the exposed group compared with the unexposed group, adjusted for gender and age (table 3, model 1). After further adjustment for smoking status, alcohol drinking, personal income and education level, the results remained statistically significant for serum MDA concentration $(\mathrm{p}=0.0001)$, serum CAT activity $(\mathrm{p}<0.0001)$, serum GSH-Px activity $(\mathrm{p}<0.0001)$ and urine concentration of $8-\mathrm{OHdG}(\mathrm{p}=0.0075)$ (table 3, model 2). Multivariate regression analysis showed that serum SOD activity was significantly $(\mathrm{p}<0.0001)$ lower in the exposed group than in the unexposed group, adjusted for sex and age (table 3, model 1), which remained significantly lower after further adjusting for smoking status, alcohol drinking, personal income and education level $(\mathrm{p}<0.0001)$ (table 3, model 2). Furthermore, urine concentration of 8-OHdG was also significantly different among varied age groups in both model 1 and model 2 , with $p$ values of less than 0.001 and 0.002 (data shown in online supplementary appendix A and appendix B). Table 4 shows the difference in serum MDA concentration between the exposed and unexposed groups, with analysis for subgroups categorised by age, sex, smoking status, alcohol drinking and education level. Similar results were reported for serum activities of CAT, SOD and GSH-Px, and urine 8-OHdG concentration (table 4). $\mathrm{Cr}(\mathrm{VI})$ exposure and smoking 
Table 2 Demographic characteristics of the study participants

\begin{tabular}{|c|c|c|c|c|}
\hline \multirow[b]{2}{*}{ Variables } & \multirow{2}{*}{$\begin{array}{l}\text { All } \\
(n=626)\end{array}$} & \multicolumn{2}{|c|}{ Hexavalent chromium } & \multirow[b]{2}{*}{$P$ values* } \\
\hline & & $\begin{array}{l}\text { Exposure } \\
(n=319)\end{array}$ & $\begin{array}{l}\text { No exposure } \\
(n=307)\end{array}$ & \\
\hline Age (years) & $60.34 \pm 10.57$ & $61.21 \pm 9.36$ & $59.44 \pm 11.64$ & 0.0377 \\
\hline Sex, n (\%) & & & & $<0.0001$ \\
\hline Male & 179 (28.59) & 69 (21.63) & $110(35.83)$ & \\
\hline Female & 447 (71.41) & $250(78.37)$ & $197(64.17)$ & \\
\hline Education level, n (\%) & & & & $<0.0001$ \\
\hline Primary school or lower & $342(54.63)$ & $146(45.77)$ & 196 (63.84) & \\
\hline Middle school or higher & $283(45.21)$ & $173(54.23)$ & $110(35.83)$ & \\
\hline Occupation, n (\%) & & & & 0.0665 \\
\hline Farmer & 589 (94.09) & 295 (92.48) & $294(95.77)$ & \\
\hline Others & $37(6.91)$ & $24(7.52)$ & $13(4.23)$ & \\
\hline Smoking status, n (\%) & & & & 0.0049 \\
\hline No & $458(73.16)$ & $249(75.86)$ & 209 (68.08) & \\
\hline Yes & $168(26.84)$ & 70 (21.94) & 98 (31.27) & \\
\hline Alcohol drinking, n (\%) & & & & 0.0033 \\
\hline No & $511(81.63)$ & $275(86.21)$ & $236(77.85)$ & \\
\hline Yes & $114(18.21)$ & $44(13.79)$ & $70(22.80)$ & \\
\hline Marital status, n (\%) & & & & 0.5424 \\
\hline Married & $580(92.65)$ & $298(93.42)$ & $282(91.86)$ & \\
\hline Others & $45(7.19)$ & $21(6.58)$ & $24(7.82)$ & \\
\hline Personal income (¥), n (\%) & & & & 0.9049 \\
\hline$<2000$ & $285(45.53)$ & $148(46.39)$ & $137(44.63)$ & \\
\hline $2000-5000$ & $152(24.28)$ & $76(23.82)$ & $76(24.76)$ & \\
\hline$>5000$ & 189 (30.19) & 95 (29.78) & $94(30.62)$ & \\
\hline
\end{tabular}

${ }^{*}$ A Student's t-test was used for continuous variables, and a $\chi^{2}$ test was used for categorical variables.

have an interaction effect on GSH-Px activity. $\mathrm{Cr}(\mathrm{VI})$ exposure and alcohol drinking also have an interaction effect on GSH-Px activity (table 4).

The length of residence positively associated with the oxidative levels (table 5), with a mean of 45 years and SD of 13 years. Both serum CAT activity $(p=0.0466)$ and urine 8-OHdG concentration $(\mathrm{p}=0.0242)$ increased with length of residence in the subgroup of first exposure at ages under 18 years, and serum GSH-Px activity $(p=0.0369)$ also increased with the length of residence in those first exposed at ages over 18 years.

\section{DISCUSSION}

Because $\mathrm{Cr}$ concentration or $\mathrm{Cr}(\mathrm{VI})$ concentration in environmental media samples is fairly high in exposed areas, people living in these areas are generally at high risk of being exposed to $\mathrm{Cr}(\mathrm{VI})$. Since the 1970s, villagers in the exposed areas have stopped drinking groundwater, thanks to the government's water improvement project, but they still use groundwater to irrigate fields and do some washing. Moreover, they can get exposed to soil with high $\mathrm{Cr}$ concentration through their hands and skin when cultivating. Thus, villagers in exposed areas may get in contact with $\mathrm{Cr}(\mathrm{VI})$ through cutaneous or hand-tomouth route. ${ }^{5}$ Villagers can also get exposed to higher $\mathrm{Cr}$ concentrations through respiration. ${ }^{8}$ Therefore, with all these exposure pathways, people living in the $\mathrm{Cr}(\mathrm{VI})$-exposed areas may have a higher risk of being exposed to $\mathrm{Cr}$ compared with those in unexposed areas.

The results of this study indicate that, adjusting for possible confounders, people living in $\mathrm{Cr}(\mathrm{VI})$-exposed areas have higher levels of lipid and DNA damage than those in unexposed areas. In addition, $\mathrm{Cr}(\mathrm{VI})$ exposure affects the antioxidant system, such as by activating or damaging the antioxidant system. ${ }^{17}{ }^{24}$ Besides,sex, age, smoking status and alcohol drinking affect the oxidative levels. Moreover, longer residence in exposed areas may increase the health risk.

Many studies have shown a significant increase of MDA in trivalent chromium $[\mathrm{Cr}(\mathrm{III})]$-exposed workers and populations compared with unexposed groups, ${ }^{25} 26$ and $\mathrm{Cr}(\mathrm{VI})$-exposed workers also have elevated MDA levels compared with unexposed workers. ${ }^{27}$ In our study, we find that the MDA concentration of the exposed group 


\begin{tabular}{|c|c|c|c|c|c|}
\hline Parameter & Model & $\begin{array}{l}\text { Exposure } \\
\text { (Lsmean } \pm \text { SE) } \\
\end{array}$ & $\begin{array}{l}\text { No exposure } \\
\text { (Lsmean } \pm \text { SE) }\end{array}$ & $\boldsymbol{\beta}^{\star}$ & $P$ values \\
\hline \multirow[t]{2}{*}{$\mathrm{MDA}(\mathrm{nmol} / \mathrm{mL})$} & Model 1 & $3.62 \pm 0.06$ & $3.29 \pm 0.06$ & 0.33 & 0.0001 \\
\hline & Model 2 & $3.65 \pm 0.07$ & $3.33 \pm 0.06$ & 0.32 & 0.0001 \\
\hline \multirow[t]{2}{*}{$\mathrm{SOD}(\mathrm{U} / \mathrm{mL})$} & Model 1 & $53.87 \pm 0.90$ & $68.80 \pm 0.85$ & -14.92 & $<0.0001$ \\
\hline & Model 2 & $54.06 \pm 1.02$ & $68.99 \pm 0.95$ & -14.93 & $<0.0001$ \\
\hline \multirow[t]{2}{*}{ GSH-Px (U/mL) } & Model 1 & $197.47 \pm 4.44$ & $153.77 \pm 4.12$ & 43.69 & $<0.0001$ \\
\hline & Model 2 & $194.99 \pm 5.00$ & $149.33 \pm 4.64$ & 45.66 & $<0.0001$ \\
\hline \multirow[t]{2}{*}{ CAT (U/mL) } & Model 1 & $4.86 \pm 0.15$ & $3.31 \pm 0.14$ & 1.55 & $<0.0001$ \\
\hline & Model 2 & $4.77 \pm 0.17$ & $3.17 \pm 0.16$ & 1.60 & $<0.0001$ \\
\hline \multirow[t]{2}{*}{$8-\mathrm{OHdG} \dagger(\mathrm{ng} / \mathrm{\mu mol}-\mathrm{Cre})$} & Model 1 & $0.11 \pm 0.03$ & $0.02 \pm 0.02$ & 0.08 & 0.0117 \\
\hline & Model 2 & $0.12 \pm 0.03$ & $0.03 \pm 0.03$ & 0.09 & 0.0075 \\
\hline
\end{tabular}

Model 1 is adjusted for sex and age.

Model 2 is adjusted for sex, age, personal income, education, smoking and alcohol use.

$P$ value of every model is less than 0.05 .

${ }^{*}$ Beta coefficient of regression, with the unexposed as the reference.

†Logarithm-transformed for normal distribution.

8-OHdG, 8-hydroxy-2 deoxyguanosine; CAT, catalase; Cre, creatinine; GSH-Px, glutathione peroxidase; Lsmean, least squares mean; MDA, malondialdehyde; SOD, superoxide dismutase.

is significantly higher than that in the unexposed group, adjusting for sex and age or even with the full model. The evaluated MDA concentration indicates increased rate of oxidative stress levels in the lipids of exposed populations. However, the results of the stratified analysis show that MDA concentration is not significantly affected by exposure to $\mathrm{Cr}(\mathrm{VI})$ in the subgroup that smokes or consumes alcohol. On the other hand, exposure to $\mathrm{Cr}(\mathrm{VI})$ still affects the non-smoking participants and those who do not consume alcohol. Many studies have shown that adjusting for potential confounders, smoking and alcohol drinking can elevate the concentration of MDA in both animal models and in humans. ${ }^{28}{ }^{29}$ However, we do not find significant association either between smoking and MDA concentration, or between alcohol drinking and MDA concentration. In our view, this lack of correlation could be mainly due to the strong influence of $\mathrm{Cr}(\mathrm{VI})$, which covers the effects that smoking and alcohol drinking have on the MDA concentration. There have been some discrepancies in the concentration of MDA in gender in previous studies. In $\mathrm{Cr}$ (III)-exposed populations, the MDA concentration is higher in women than that in men. ${ }^{26}$ However, in normal populations, concentration of MDA is lower in women than that in men, ${ }^{30}$ which is consistent with our results.

ROS form when $\mathrm{Cr}(\mathrm{VI})$ reduces to a lower oxidation state, and the free radicals may attack the DNA, thereby disrupting cellular functions and integrity. ${ }^{19}$ Thus DNA damage produces alterations in the DNA, strand breaks and DNA-protein crosslinks. 8-OHdG is a major oxidative adduct formed by radicals inducing damage to the DNA. ${ }^{31}$ As a biomarker of oxidative DNA damage, 8-OHdG levels directly reflect the average rate of oxidative DNA damage. ${ }^{32}$ Daily cumulative $\mathrm{Cr}(\mathrm{VI})$ exposure has a significant correlation with urinary 8-OHdG levels adjusted for covariates in workers. $273133-35$

In our study, the concentration of urine $8-\mathrm{OHdG}$ in the exposed group is significantly higher than in the unexposed group (table 3). This is consistent with previous studies focusing on occupational exposure, which indicates that $\mathrm{Cr}(\mathrm{VI})$ exposure induces the formation of ROS and causes oxidative tissue and DNA damage. ${ }^{36}$ In its turn, oxidative DNA damage can lead to consequences including cell death, mutation and malignant transformation. ${ }^{37}$ Some studies have shown that the concentration of 8-OHdG mainly correlates with the $\mathrm{Cr}(\mathrm{VI})$ concentration in the air. ${ }^{31}{ }^{34}$ Therefore, higher concentration of urinary 8-OHdG in the exposed group may be on account of higher air Cr levels. However, this relation needs further research and evidence.

In the stratified analysis, we find that the level of 8-OHdG regulated with urinary Cre in the elderly group is higher than in the younger group. In the regression model, there is a positive correlation between age and concentration of urine 8-OHdG. A study has shown that a highly significant rise in DNA damage level can be observed in leucocyte DNA in the elderly population (mean age 67 years) and middle-age group (mean age 50 years) in comparison with adults (mean age 31 years). ${ }^{38}$ These findings are consistent with ours. The reason that DNA damage increases with age may be a deficiency in the ability to remove the damage or the intensification of processes responsible for the damage formation, or both. ${ }^{38}$ Some other factors may have effects on the concentration of 8-OHdG, such as smoking status and alcohol drinking. A positive correlation between the 8-OHdG levels and smoking status has been observed, and the 8-OHdG concentration in urinary samples of smokers 


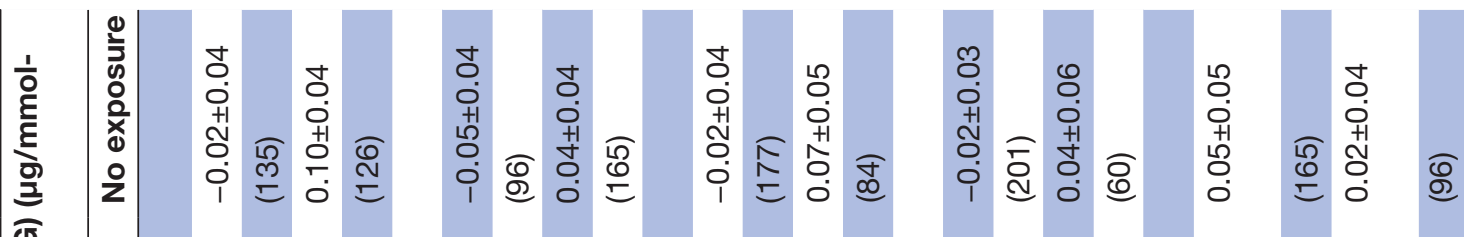

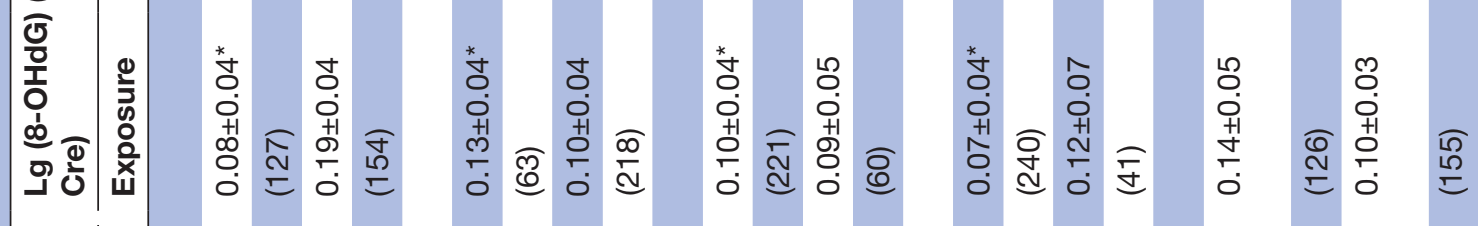

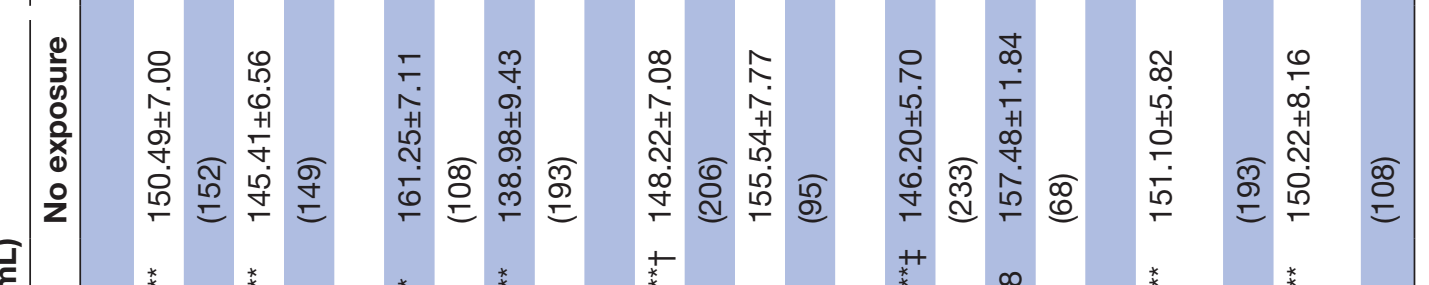

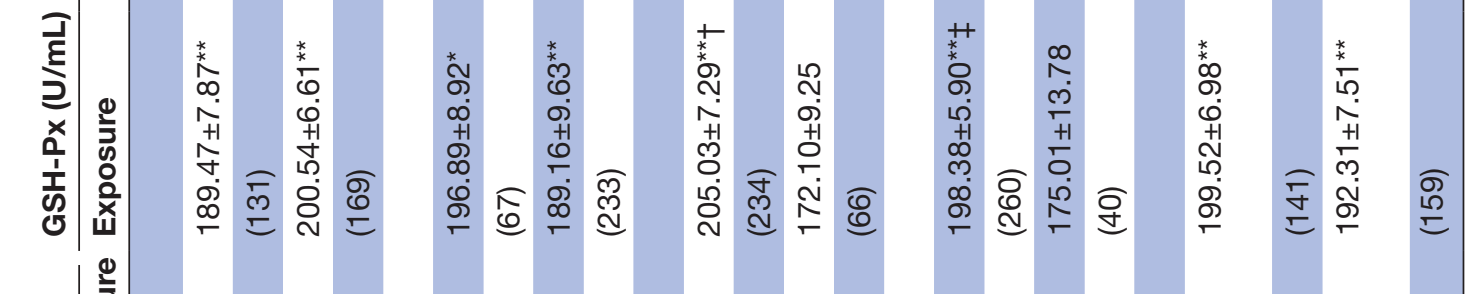

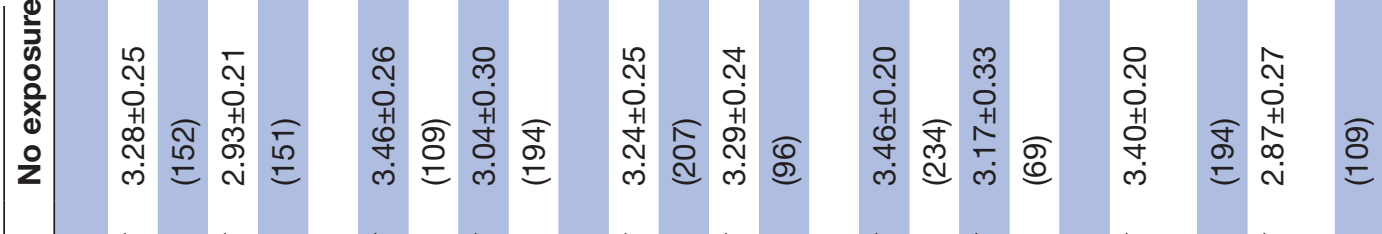

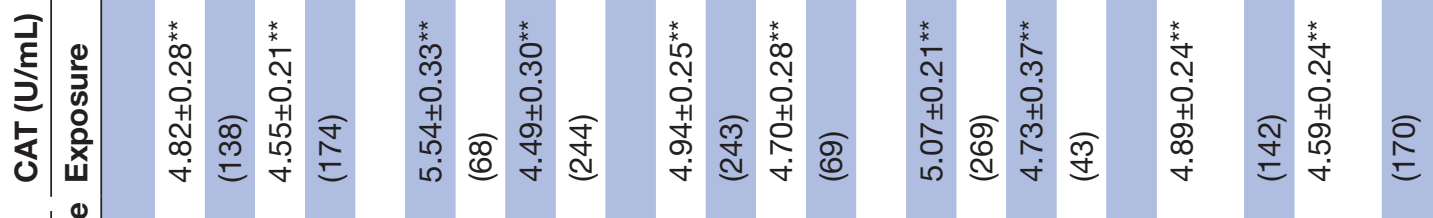

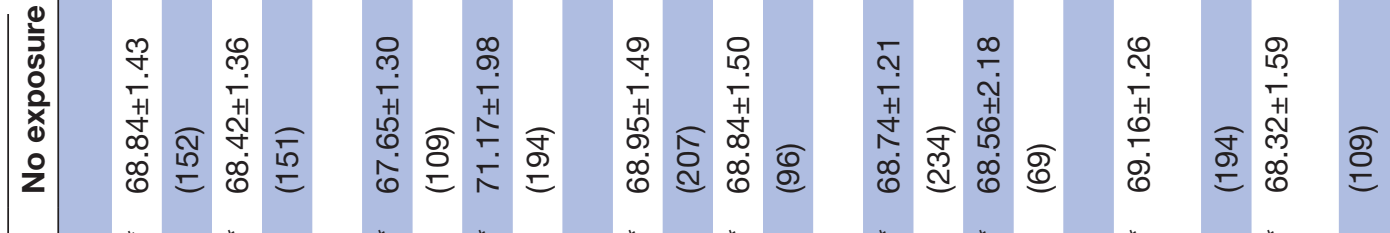

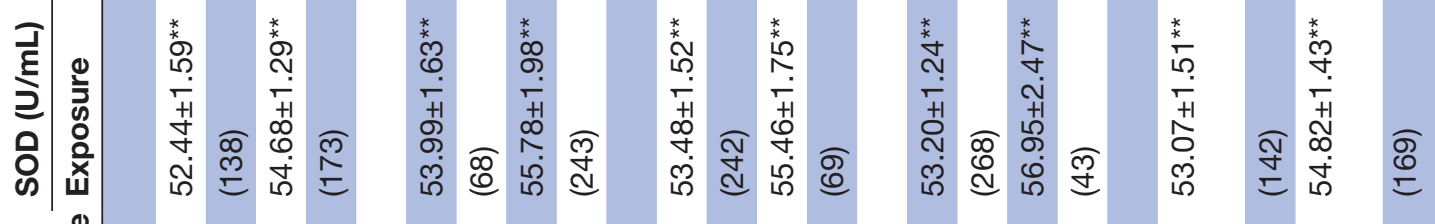

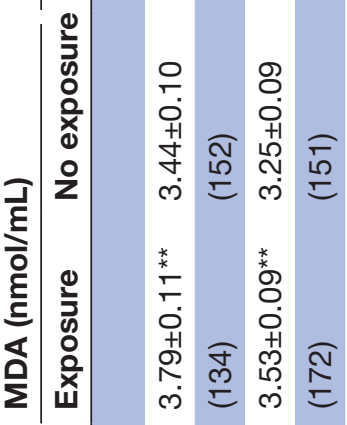

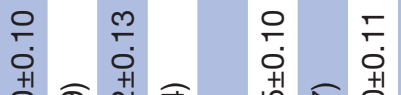

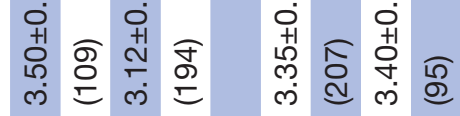

ํํำ

아 으

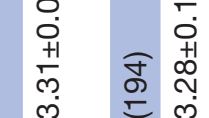

ฮ

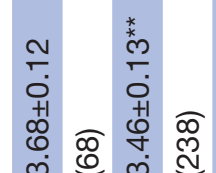

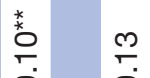

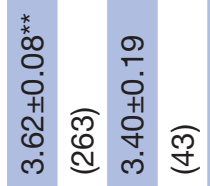

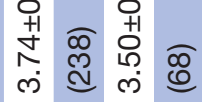

ᄃ.

옹

길

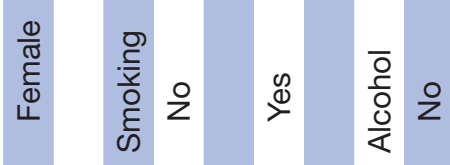
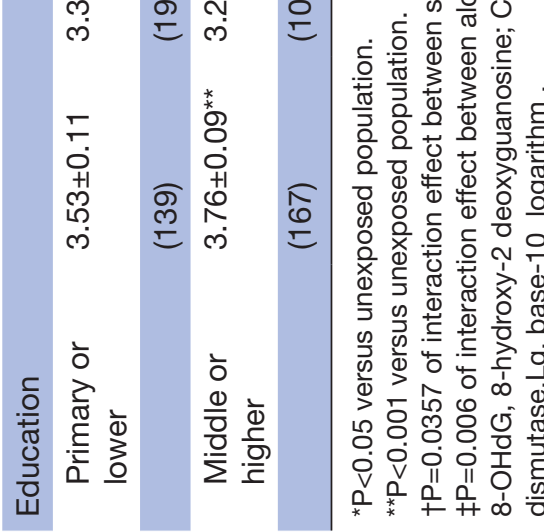

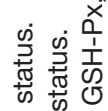

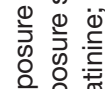

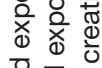

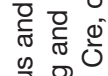

蛋

은흥

的过

罗

잉

学

궁

कั

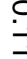

홍.

옥

옴

응

N

气

옹

\ั 
is $50 \%$ higher as compared with non-smokers. ${ }^{39}{ }^{40}$ Other studies provide evidence that ethanol can induce oxidative DNA damage in human peripheral lymphocytes in vitro and signs of increased oxidative damage compared with the non-drinking people. ${ }^{41}{ }^{42}$ In this study, we find that in both exposed and unexposed groups, smokers or drinkers exhibited a higher concentration of 8-OHdG than non-smokers or non-drinkers. This finding is also consistent with previous studies.

In response to oxidative stress and lipid peroxidation, the antioxidant mechanisms are activated. We selected GSH-Px, SOD and CAT as the three parameters to assess the antioxidant mechanisms in response to $\mathrm{Cr}(\mathrm{VI})$. Many researchers have shown that the activity of SOD is higher in the occupational $\mathrm{Cr}(\mathrm{VI})$-exposed group or $\mathrm{Cr}(\mathrm{III})$-exposed populations, ${ }^{25} 2643$ while some have shown that the activity of SOD and GSH-Px is decreased in the occupational $\mathrm{Cr}(\mathrm{VI})$-exposed group. ${ }^{27}$ GSH-Px catalyses the reduction of hydrogen peroxide to water and of organic hydroperoxides to less toxicity by using reduced glutathione, and the by-product, oxidised glutathione, is converted to reduced glutathione via the action of glutathione reductase using nicotinamide adenine dinucleotide phosphate as the electron donor. ${ }^{44}{ }^{45}$ An experiment on cells mentions that GSH-Px and CAT act in a compensatory manner to overcome oxidative stress. CAT accomplishes the basic defence at the late stages of cell growth, and GSH-Px has much higher affinity to $\mathrm{H}_{2} \mathrm{O}_{2}$ than CAT at low substrate concentration. ${ }^{46}$

In our study, we find that the activity of CAT and GSH-Px is higher in the exposed group than that in the unexposed group, which means the antioxidant system is activated. However, the activity of SOD is found to have decreased in the exposed group. Antioxidants play a protective role against free radical-induced damage. Therefore, their induction can be understood as a response to oxidative stress. However, if the exposure persists, the antioxidant function can be damaged during or after the exposure. ${ }^{132746}$ A decrease in the serum activity of SOD may be a sign of the impairment of the antioxidant system in this study. If the antioxidant systems are not able to reduce the ROS produced, then oxidative stress and oxidative damage may occur, leading to organism disorder, and even to diseases in some cases. ${ }^{17}$

In the stratified analysis, we find that $\mathrm{Cr}(\mathrm{VI})$ exposure and smoking have an effect modification on GSH-Px activity, and that $\mathrm{Cr}(\mathrm{VI})$ exposure and alcohol drinking also have an effect modification on GSH-Px activity. In the exposed group, the GSH-Px activity of non-smokers and non-drinkers is higher than smokers and drinkers. However, in the unexposed group, the GSH-Px activity of non-smokers and non-drinkers is lower than smokers and drinkers. Animal experiments have shown that alcohol consumption is able to increase oxidative stress, with a decrease in GSH-Px-1 activity and increase in GSH activities. ${ }^{45}{ }^{47} \mathrm{In}$ in vivo and in vitro experiments, exposure to cigarette smoke could increase intercellular ROS and oxidative stress, and total glutathione decreases 
dramatically. ${ }^{48} 49$ In the unexposed group, smoke and alcohol use may cause elevated activity of GSH-Px. However, in the exposed group, along with the exposure, the decrease of the activity of GSH-Px may be due to the damage of the antioxidant system. We present participants' disease status (shown in online supplementary appendix $\mathrm{C}$ ) and conduct stratified analysis according to disease status (shown in online supplementary appendix D); however, we do not see any effects on the primary results.

In the analysis of the relationship between the length of residence and oxidative levels, we find that urine 8-OHdG concentration and serum CAT activity have a dose-response relationship with years of residence in the subgroup of first exposure under 18 years old, and the serum GSH-Px activity in the subgroup of first exposure over 18 years old has a positive correlation with the length of residence. These results may indicate that longer exposure to $\mathrm{Cr}(\mathrm{VI})$ can aggravate DNA damage and activate antioxidant response. In an in vitro experiment, cells exposed to $\mathrm{Cr}(\mathrm{VI})$ can activate and impair the antioxidant system with the increase in exposure time. ${ }^{46}$ In some epidemiology studies, researchers found that different lengths of residence may have an effect on the oxidative stress levels of female immigrants exposed to heavy metal. ${ }^{50} \mathrm{~A}$ cohort study of chromate production workers indicates that length of exposure is an important explanatory variable to the increase of lung cancer risk. ${ }^{51}$ Our study reveals that long-term exposure to $\mathrm{Cr}(\mathrm{VI})$ can continuously increase the health risk.

The main limitation of our study is that individual exposure data are not obtained. This may lead to a major problem, which is that we could not relate the internal exposure to oxidative parameters. We will keep working on this project, trying to get more data to give a further clarification of the relationship between the health effects and $\mathrm{Cr}(\mathrm{VI})$ contamination. In addition, homogeneity of the exposed and unexposed groups is not satisfactory. For this reason, we used a multiple regression model and stratified analysis to adjust for possible confounders. Also we did not take people's nutritional status into consideration, mainly because participants are all living in the rural areas of Jinzhou, Liaoning province, whose diet and living habits are basically the same.

In conclusion, our research demonstrates that people living around the ferroalloy factory are at higher health risk. After adjusting for potential confounders, the results show elevated oxidative stress and oxidative damage in the population exposed to $\mathrm{Cr}(\mathrm{VI})$ compared with the unexposed population. Moreover, the effect modification presented in the stratified analysis may indicate that the combination of both $\mathrm{Cr}(\mathrm{VI})$ and alcohol, or both $\mathrm{Cr}(\mathrm{VI})$ and smoking, may cause damage to the antioxidant system. In addition, longer residence in areas exposed to $\mathrm{Cr}(\mathrm{VI})$ would increase people's oxidative levels.

Contributors $\mathrm{JX}$ analysed and interpreted the data and was a major contributor to writing the manuscript. MZ, LP and RZ participated in the field work and experimental work. XL and LW prepared all the things relating to the field work. MY was in charge of polishing the manuscript and conducting some statistical analyses. QX designed the study and arranged the field work. All authors read and approved the final manuscript.

Funding This research was sponsored by the CAMS Innovation Fund for Medical Sciences (2017-12M-1-009)

Competing interests None declared.

Patient consent Not required.

Ethics approval The study was approved by the Institutional Review Board (IRB) at the Institute of Basic Medical Sciences, Chinese Academy of Medical Sciences.

Provenance and peer review Not commissioned; externally peer reviewed.

Data sharing statement The data sets used and/or analysed in the current study are available from the corresponding author on reasonable request.

Open access This is an open access article distributed in accordance with the Creative Commons Attribution Non Commercial (CC BY-NC 4.0) license, which permits others to distribute, remix, adapt, build upon this work non-commercially, and license their derivative works on different terms, provided the original work is properly cited and the use is non-commercial. See: http://creativecommons.org/ licenses/by-nc/4.0/

(C) Article author(s) (or their employer(s) unless otherwise stated in the text of the article) 2018. All rights reserved. No commercial use is permitted unless otherwise expressly granted.

\section{REFERENCES}

1. Kim HS, Kim YJ, Seo YR. An overview of carcinogenic heavy metal: molecular toxicity mechanism and prevention. J Cancer Prev 2015;20:232-40.

2. Qu X, Ren Z, Zhang M, et al. Sediment heavy metals and benthic diversities in Hun-Tai River, northeast of China. Environ Sci Pollut Res Int 2017;24:10662-73.

3. Mazurek R, Kowalska J, Gąsiorek M, et al. Assessment of heavy metals contamination in surface layers of Roztocze National Park forest soils (SE Poland) by indices of pollution. Chemosphere 2017;168:839-50.

4. Navarrete IA, Gabiana CC, Dumo JR, et al. Heavy metal concentrations in soils and vegetation in urban areas of Quezon City, Philippines. Environ Monit Assess 2017;189:145.

5. Oliver MA. Soil and human health: a review. Eur J Soil Sci 1997;48:573-92.

6. Toxicguide for chromium. US Department of health and human services public health service agency for toxic substances and disease registry. 2012.

7. Linos A, Petralias A, Christophi CA, et al. Oral ingestion of hexavalent chromium through drinking water and cancer mortality in an industrial area of Greece--an ecological study. Environ Health 2011;10:50.

8. Kerger BD, Butler WJ, Paustenbach DJ, et al. Cancer mortality in chinese populations surrounding an alloy plant with chromium smelting operations. J Toxicol Environ Health A 2009;72:329-44.

9. Chromium, nickel and welding. IARC monographs on the evaluation of carcinogenic risks to humans. 1990;49:1-648.

10. Welling R, Beaumont JJ, Petersen SJ, et al. Chromium VI and stomach cancer: a meta-analysis of the current epidemiological evidence. Occup Environ Med 2015;72:151-9.

11. Beaumont JJ, Sedman RM, Reynolds SD, et al. Cancer mortality in a Chinese population exposed to hexavalent chromium in drinking water. Epidemiology 2008;19:12-23.

12. Valko M, Morris H, Cronin MT. Metals, toxicity and oxidative stress. Curr Med Chem 2005;12:1161-208.

13. Patlolla AK, Barnes C, Yedjou C, et al. Oxidative stress, DNA damage, and antioxidant enzyme activity induced by hexavalent chromium in Sprague-Dawley rats. Environ Toxicol 2009;24:66-73.

14. Jomova K, Valko M. Advances in metal-induced oxidative stress and human disease. Toxicology 2011;283(2-3):65-87.

15. Sharma B, Singh S, Siddiqi NJ. Biomedical implications of heavy metals induced imbalances in redox systems. Biomed Res Int 2014;2014:1-26.

16. Dalle-Donne I, Rossi R, Colombo R, et al. Biomarkers of oxidative damage in human disease. Clin Chem 2006;52:601-23.

17. Sharma N. Free radicals, antioxidants and disease. Biology and Medicine 2014;06. 
18. Kaur R, Kaur J, Mahajan J, et al. Oxidative stress--implications, source and its prevention. Environ Sci Pollut Res Int 2014;21:1599-613.

19. Bagchi D, Vuchetich PJ, Bagchi M, et al. Induction of oxidative stress by chronic administration of sodium dichromate [chromium VI] and cadmium chloride [cadmium II] to rats. Free Radic Biol Med 1997;22:471-8.

20. Edwin N, Frankel WEV. Formation of malonaldehyde from lipid oxidation products. Biochmicu et Biophvsicu Acta 1983;754:264-70.

21. GB 7467-87. Water quality-Determination of chrommium (VI)-1.5 Diphenylcarbohydrazide spectrophotometric method: Ministry of Environmental Protection of the People's Republic of China, 1987.

22. HJ 491-2009. Soil quality-determination of total chromium -flame atomic absorption spectrometry: Ministry of Environmental Protection of the People's Republic of China, 2009.

23. HJ 777-2015. Ambient air and waste gas from stationary sources emission-determination of metal elements in ambient particle matterInductively coupled plasma optical emission spectrometry: Ministry of Environmental Protection of the People's Republic of China, 2015.

24. Junaid M, Hashmi MZ, Malik RN, et al. Toxicity and oxidative stress induced by chromium in workers exposed from different occupational settings around the globe: A review. Environ Sci Pollut Res Int 2016;23:20151-67.

25. Ambreen K, Khan FH, Bhadauria S, et al. Genotoxicity and oxidative stress in chromium-exposed tannery workers in North India. Toxicol Ind Health 2014;30:405-14.

26. Khan FH, Ambreen K, Fatima G, et al. Assessment of health risks with reference to oxidative stress and DNA damage in chromium exposed population. Sci Total Environ 2012;430:68-74.

27. Wang TC, Song YS, Wang H, et al. Oxidative DNA damage and global DNA hypomethylation are related to folate deficiency in chromate manufacturing workers. J Hazard Mater 2012;213214:440-6.

28. Megson IL, Haw SJ, Newby DE, et al. Association between exposure to environmental tobacco smoke and biomarkers of oxidative stress among patients hospitalised with acute myocardial infarction. PLoS One 2013;8:e81209.

29. McCaskill ML, Kharbanda KK, Tuma DJ, et al. Hybrid malondialdehyde and acetaldehyde protein adducts form in the lungs of mice exposed to alcohol and cigarette smoke. Alcohol Clin Exp Res 2011;35:1106-13.

30. Bloomer RJ, Fisher-Wellman KH. Blood oxidative stress biomarkers: influence of sex, exercise training status, and dietary intake. Gend Med 2008;5:218-28.

31. Kuo HW, Chang SF, Wu KY, et al. Chromium (VI) induced oxidative damage to DNA: increase of urinary 8-hydroxydeoxyguanosine concentrations (8-OHdG) among electroplating workers. Occup Environ Med 2003;60:590-4.

32. Floyd RA. The role of 8-hydroxyguanine in carcinogenesis. Carcinogenesis 1990;11:1447-50.

33. Pan $\mathrm{CH}$, Jeng $\mathrm{HA}$, Lai $\mathrm{CH}$. Biomarkers of oxidative stress in electroplating workers exposed to hexavalent chromium. J Expo Sci Environ Epidemiol 2018;28.

34. Li P, Gu Y, Yu S, et al. Assessing the suitability of 8-OHdG and micronuclei as genotoxic biomarkers in chromate-exposed workers: a cross-sectional study. BMJ Open 2014;4:e005979.

35. Ni W, Huang $Y$, Wang $X$, et al. Associations of neonatal lead, cadmium, chromium and nickel co-exposure with DNA oxidative damage in an electronic waste recycling town. Sci Total Environ 2014:472:354-62.

36. Bagchi D, Hassoun EA, Bagchi M, et al. Chromium-induced excretion of urinary lipid metabolites, DNA damage, nitric oxide production, and generation of reactive oxygen species in SpragueDawley rats. Comp Biochem Physiol C Pharmacol Toxicol Endocrinol 1995; 110:177-87.

37. Wise SS, Holmes AL, Wise JP. Hexavalent chromium-induced DNA damage and repair mechanisms. Rev Environ Health 2008;23:39-57.

38. Olinski R, Siomek A, Rozalski R, et al. Oxidative damage to DNA and antioxidant status in aging and age-related diseases. Acta Biochim Pol 2007;54:11-26.

39. Kasai $\mathrm{H}$. Analysis of a form of oxidative DNA damage, 8-hydroxy2 '-deoxyguanosine, as a marker of cellular oxidative stress during carcinogenesis. Mutat Res 1997;387:147-63.

40. Steffen Loft KV, Ewertz M. Anne TjOnneland, Kim Overvad,Henrik Enghusen Poulsen. Oxidative DNA damage estimated by 8-hydroxydeoxyguanosine excretion in humans: influence of smoking, gender and body mass index. Cardnogeoesis 1992;13:2241-7.

41. Yan Y, Yang JY, Mou YH, et al. Possible metabolic pathways of ethanol responsible for oxidative DNA damage in human peripheral lymphocytes. Alcohol Clin Exp Res 2011;35:1-9.

42. Rendón-Ramírez A, Cortés-Couto M, Martínez-Rizo AB, et al. Oxidative damage in young alcohol drinkers: A preliminary study. Alcohol 2013;47:501-4.

43. Junaid M, Hashmi MZ, Malik RN. Evaluating levels and health risk of heavy metals in exposed workers from surgical instrument manufacturing industries of Sialkot, Pakistan. Environ Sci Pollut Res Int 2016;23:18010-26.

44. Gromadzińska J, Wasowicz W, Sklodowska M, et al. The influence of atmospheric chromium on selenium content and glutathione peroxidase activity in blood of tannery workers. Environ Health Perspect 1996;104:1312-6.

45. Bailey SM, Patel VB, Young TA, et al. Chronic ethanol consumption alters the glutathione/glutathione peroxidase-1 system and protein oxidation status in rat liver. Alcohol Clin Exp Res 2001;25:726-33.

46. Asatiani N, Kartvelishvili T, Abuladze M, et al. Chromium (VI) can activate and impair antioxidant defense system. Biol Trace Elem Res 2011;142:388-97.

47. Kaphalia L, Boroumand N, Hyunsu J, et al. Ethanol metabolism, oxidative stress, and endoplasmic reticulum stress responses in the lungs of hepatic alcohol dehydrogenase deficient deer mice after chronic ethanol feeding. Toxicol Appl Pharmacol 2014;277:109-17.

48. Colombo G, Dalle-Donne I, Orioli M, et al. Oxidative damage in human gingival fibroblasts exposed to cigarette smoke. Free Radic Biol Med 2012;52:1584-96.

49. Ignatowicz E, Woźniak A, Kulza M, et al. Exposure to alcohol and tobacco smoke causes oxidative stress in rats. Pharmacol Rep 2013;65:906-13.

50. Wu WT, Wu CC, Lin YJ, et al. Changing blood lead levels and oxidative stress with duration of residence among Taiwan immigrants. J Immigr Minor Health 2013;15:1048-56.

51. Gibb H, Hoffman $\mathrm{H}$, Haver C. Biologic implications from an epidemiologic study of chromate production workers. Open Epidemiol J 2011;4:54-9. 